\title{
Networks of Global Interaction
}

\author{
Paula Uimonen \\ Department of Social Anthropology, Stockholm University
}

\begin{abstract}
Although the correlation between the Internet and globalisation is well recognised, we know relatively little about the social impact of the networked world order. Based on research on Internet growth in developing countries, this article seeks to identify some of its most salient features and how these influence, and in turn are influenced by, the broader processes of modernisation and globalisation. Through a closer examination of the social and cultural embeddedness of the Internet, the article will discuss how the organisational principle of networks is becoming more prominent in contemporary society, leading to the rise of the networked society. Rather than representing a post-modern social form, the networked society reaffirms some of the most fundamental, and rather contradictory, aspects of modernity, especially the dual processes of globalisation and individualisation. Representing a new medium for communication and interaction, the Internet allows users to establish and maintain social relations on a global scale. Rather than erasing local identities, these 'glocal' interactions have a tendency to enforce a localised sense of belonging. Nonetheless, the boundarycrossing nature of networks also has a tendency to make existing boundaries rather fuzzy and subject to mediated redefinition and re-imagining.
\end{abstract}

Following decades of accelerated globalisation, the centres and peripheries of the world are now interlinked in innumerable ways. While we may have become accustomed to thinking of globalisation in terms of a one-way process whereby the centres of the world are exercising their power over the less powerful peripheries, recent events have brought the validity of this assumption into question. Events in distant corners of the world are increasingly affecting the lives of people who reside in the hubs of the global flow, and vice versa.

Global interconnectedness is organised into networks, as exemplified by the events of 11 September 2001. While many observers interpreted the terrorist attacks on the United States in terms of a 'clash of civilisations', I would argue that we witnessed a rather different type of conflict altogether. Instead, 11 September represented a clash between two different organisational principles; it was a violent encounter between territorial boundedness and boundarycrossing networks. In the aftermath of the attacks, media reporting and analyses switched between elusive terrorist networks and the visible manifestations of localised patriotism. Meanwhile, the underlying dilemma remained unsolved: how can the institutions erected to defend the integrity and sovereignty of a

* This article builds on some of the findings of my recently completed research on the social dynamics of Internet development in developing countries (Uimonen 2000). 
state be applied to an opponent that resides nowhere and is organised in networks that reach everywhere?

Networks of global interconnectedness are also characteristic of the Internet, a decentralised, interactive medium that connects people from around the world. In September 2002, it was estimated that the number of Internet users had surpassed 600 million. ${ }^{1}$ It is rather remarkable that a medium that only became publicly available less than a decade ago is now within the reach of some $10 \%$ of the world population. Granted, Internet access continues to be unevenly distributed between and within countries. Nonetheless, the Internet is now accessible from every country in the world and if popular demand is anything to go by, it will only continue to grow in the years to come.

Commonly defined as the network of networks, the Internet provides us with an opportunity to understand the organisational principles of networks. They are by no means a new form of social organisation. If anything, networking has undoubtedly played a role throughout time in all societies. Nonetheless, in today's globalised world, networks are taking on a new significance with the Internet providing a means through which people are able to establish and maintain social relations on a global scale. It is not unreasonable, therefore, that the rapid expansion of the Internet has been interpreted in terms of the emergence of what could be defined as the network society (Castells 1996) or the networked society (Uimonen 2001).

In this article, I will analyse the relation between the Internet and globalisation, with a focus on developing countries. By allowing users to communicate and interact irrespective of physical distance, the Internet is contributing to a higher degree of global interconnectedness. While these global linkages enhance the appreciation of the world as a whole, they also enforce a localised sense of belonging. In the following paper, I will analyse the social and cultural characteristics of the Internet and how these relate to the broader processes of modernisation and globalisation. I will argue that the Internet is contributing to the construction of a networked world order, the organising principles of which are having a profound impact on societies around the world.

\section{The Social Implications of the Culture of Networking}

While actively participating in the expansion of the Internet throughout the developing world, Internet pioneers have not only contributed to the spread of a new technology but also of a culture. To its pioneers, the cultural essence of the Internet relates to the open sharing of knowledge of and by way of the Internet among individuals around the world. Representing the social nodes of the Internet, Internet pioneers are the primary carriers of this culture, their activities being informed by what they often refer to as the 'spirit of the Internet'. In my analysis of the experiences and visions of these Internet pioneers, I have used the term 'culture of networking' to capture the social and cultural embeddedness of the Internet. The culture of networking refers both to the practice of networking and networking as a cultural construct, the Internet representing a

${ }^{1} 605.60$ million users, estimate as of September 2002, Nua Internet Surveys, http:// www.nua.com/surveys/how_many_online/index.html. 
combination of the two, and its development being the result of culturally mediated social agency, as exemplified by the role of the Internet pioneers.

As is the case with all technological development, the Internet has its own social dynamics, representing a combination of the material composition of the technology and the social settings in which they are embedded (Schroeder 1996). In the case of the Internet, the technological characteristics revolve around the ability to connect disparate computers through networks. Initially designed to allow researchers to share costly computer resources, the Internet has developed into a tool for communication and information sharing. Today, communication and interaction are the main features of the Internet, as evidenced in the popularity of e-mail, electronic discussion forums and on-line chat rooms.

With regards to its cultural characteristics, the culture of networking reflects the technical interfaces of the Internet and the ideas and values that have accompanied their development. The origins of the culture of networking can be traced back to the late 1960s when the Internet was first developed under the auspices of the Advanced Research Projects Agency (ARPA) of the US Department of Defence. Known as the ARPANET, this project was aimed at developing a computer communications system for researchers (Hafner and Lyon 1996). The development of the technical protocols of the ARPANET set the foundation for what has been called the 'ethos of the Net', an important aspect of which was the open sharing of information (Naughton 2000, p. 138). The ability to communicate and share resources, through the intermediary of an open, decentralised technology devoted to the uninterrupted flow of information came to represent the nucleus of the culture of networking.

The culture of networking was in turn influenced by broader societal trends, especially the ideals of the counter-culture movements of the 1960s and 1970s. These movements were particularly active in the milieus in which the culture of networking originally evolved. In the United States, the universities of Berkeley and Stanford formed part of the San Francisco Bay Area, an area renowned for its conglomeration of alternative lifestyles and a hotbed of counter-cultural activity. This was also the environment in which the Mecca of computing, Silicon Valley, evolved-in the midst of, and strongly informed by, the counter-cultural ethos of the time (Castells 1996, pp. 53-60; 345-58). In effect the cultural origin of the Internet translated into a 'computer counter-culture' characterised by a 'libertarian/utopian vision' and 'counter-cultural ideology' that 'framed its [the Internet's] utilisation' (ibid., pp. 353-54).

Inspired by the counter-cultural movements of the 1960s and 1970s, the culture of networking has a pronounced libertarian ethos. On the Internet the libertarian sanctity of the individual is symbolically expressed in the free flow of information that has characterised the Internet since its inception. Individual freedom is also embedded in the decentralised and interactive nature of the Internet, which sets it apart from other media and communication technologies. The Internet allows individual users to be both consumers and producers of information. It further allows users to communicate individually as well as collectively.

Reflecting the global reach of the Internet, another distinguishing feature of the culture of networking is its cosmopolitan ethos. From the outset, the Internet was used by researchers around the world to communicate and share information. Although Internet access was mainly available in rich developed coun- 
tries, in the 1980s it was spreading to the developing world and by the late 1990s it was available in most countries of the world. Today, some $10 \%$ of the world population uses the Internet to communicate and interact with people from around the world and to access informational resources of an unprecedented scale and scope.

As reflected in the libertarian and cosmopolitan ethos of the culture of networking, the Internet is a medium that traverses existing boundaries. Generally defined as the 'network of networks', the Internet allows users to establish and maintain social relations that cross existing social and cultural boundaries. The crossing of institutional boundaries allows users to bypass social hierarchies, while the crossing of national boundaries provides users with a means of traversing the cultural boundaries of their societies, thus enhancing the libertarian and cosmopolitan underpinnings of the culture of networking.

It is in order to capture the boundary-crossing nature of the Internet that I define its social and cultural embeddedness in terms of the culture of networking. From an anthropological perspective, networks represent a useful concept with which to appreciate relations that stretch across a variety of social environments and the ways in which social agents cross and manipulate boundaries (Hannerz 1980). This anthropological understanding offers a much broader and more applicable appreciation of networks than Castells' definition of networks as a set of interconnected nodes (1996, p. 470). The Internet offers a vantage point for the appreciation of the organisational principle of networks. One of the most distinguishing features of networks is that they are decentralised, as exemplified by the individualised basis of the Internet. The decentralised character of networks translates into a more vertical form of social organisation than that of hierarchical structures. I am by no means suggesting that networks are completely devoid of structural ranking. After all, networks intersect in nodes that differ in social positioning. Nonetheless, whether composed of individuals or institutions, these nodes tend to be highly mobile and ever changing. This dynamic character of networks renders a more flexible form of organisation, one that traverses existing boundaries. Combined, the decentralised and dynamic nature of networks translates into a form of social organisation that follows the principle of flow rather than structure.

The boundary-crossing nature of the Internet is having a profound impact on the organisation of our societies. I am by no means suggesting some form of technological determinism according to which technology represents an external force that affects society from the outside. Quite the contrary, it is the social and cultural embeddedness of a given technology that determines, and is determined by, its social impact. In the case of the Internet, we are witnessing the exponential spread of a technology that allows users to communicate and interact in new ways, thus strengthening contemporary social processes in fundamental ways.

Most significantly, the Internet reflects and influences the dual processes of individualisation and globalisation that are prominent features of contemporary, complex societies. As noted above, individualisation and globalisation are prominently manifested in the libertarian and cosmopolitan ethos of the culture of networking, reflecting the individualised nature and global reach of the Internet. I shall delve more on Internet and globalisation in the following pages. At this point I would, firstly, just like to underline the impact of the Internet on individualism. Research on Internet use has shown that the Internet enhances 
social interaction at a distance as well as locally (for an overview, see Castells 2001). This interaction revolves around individuals who interact in and through networks, leading researchers to suggest that a new form of sociability in contemporary society is that of networked individualism (ibid., p. 129).

\section{Modernisation in a Networked World Order}

What makes the Internet such a powerful tool for globalisation is the organisational principle of boundary-crossing networks that is inherent to this technology. By facilitating the transnational flow of people, goods and information, the Internet is lending validity to the conceptualisation of the global landscape of modernity in terms of a network of networks (Hannerz 1992a). Nonetheless, the pervasiveness of the organisational principle of networking is also bringing forth some of the inherent contradictions of the modern condition, especially when appreciated in terms of the logic of boundary-crossing flow as opposed to the bounded structure of the nation state.

Castells (1996) has suggested that the information age represents a new social structure, the 'network society', the material underpinnings of which radically differ from the modern, industrial society. While industrial society relied on the 'space of places', the network society is structured according to a new spatial logic that he refers to in terms of 'space of flows' (ibid., p. 378). Similarly, while modernity has been perceived in terms of the dominance of clock time over space and society', the network society is characterised by de-localised 'timeless time' (ibid., pp. 432-33). Castells (1998, p. 350) concludes that the network society is 'made up of networks of production, power, and experience, which construct a culture of virtuality in the global flows that transcend time and space'. While I disagree with some of Castells' postulations, I find his emphasis on the organisational logic of networks to be of great value. Although Castells seems to overestimate the nature and scope of social transformation-the concepts of timeless time, space of flow and culture of virtuality indicating a post-modern reading of society with limited applicability-I would agree with his analysis on the growing significance of networks. When viewed from the perspective of Internet development, it becomes quite clear that the principle of networking is becoming more commonplace around the world.

Based on my own research, I would suggest that the social impact of the global diffusion of the Internet is better captured by the term networked societies than the concept 'network society'. The Internet is not ushering in a new social form. Rather, the Internet is contributing to the interconnectedness of societies. Meanwhile, the primary form of social organisation and political legitimacy continues to be the nation state. While the Internet is bringing forth the elasticity of national boundaries, the nation state continues to be conceptualised as a bounded, sovereign entity. And herein lays the inherent dilemma of the networked world order.

By strengthening the processes of globalisation and individualisation, the Internet is reaffirming the foundations of modernity, while bringing forth some of its inherent contradictions. The very concept of the unitary nation state is an aspect of globalisation, as is the construction of the individual (Robertson 1992). If anything, both individualisation and globalisation represent two sides of modernisation (Beck 1994). Nonetheless, interrelated as these processes are, they 
are also contradictory. Just like globalisation is considered to be disruptive of societal boundedness, so is the atomisation of individualisation considered to be disruptive of the collective whole. This contradictory relation between individuals, society and the world arises from a rather illusory modernist notion of societies as bounded entities, a view that is increasingly called into question by contemporary scholars. Barth (1992) has, for instance, offered a more adequate definition of society in terms of disordered open systems, a perspective that takes overlapping social networks with crosscutting boundaries into greater account.

When viewed from the perspective of the Internet development, these contradictory aspects of modernity become quite apparent. Forming the ethnographic basis of my research on Internet development in developing countries, the experiences of the Internet pioneers provide ample evidence on the contradictory dynamics of transnational networks. Drawn from a variety of professional backgrounds, Internet pioneers form a heterogeneous category of people who have actively contributed to the deployment of the Internet throughout the developing world. Many Internet pioneers come from developing countries, their activities being aimed at spreading connectivity in their countries of origin. Others come from developed countries, their involvement in Internet development in developing countries stemming from a desire to spread the benefits of the Internet to the whole world. While introducing and spreading the Internet in developing countries, Internet pioneers tend to get involved in the inner workings of the state apparatus. Their involvement is often centred on awareness-raising activities, aimed at improving the knowledge of political decision-makers on the social and economic significance of the Internet. In so doing, they rely on their own expertise as well as the expertise available through the transnational networks of Internet pioneers. If anything, networking forms an important method in the activities of the Internet pioneers, in addition to brokering which will be discussed later.

Responses to the activities of Internet pioneers vary tremendously, depending on the social and political characteristics of the national contexts in which they operate. Historically shaped responses to globalisation, the dominant political culture, and the structuring of the state apparatus represent influential factors. In general, the more integrated a country is with global trends, the easier the adaptation of the Internet. In countries that have a history of isolation from the global arena, the state tends to be far more resistant to the Internet. In either case, the government's response to the Internet is informed by the political culture of the ruling regime, i.e. the state's ability and desire to exercise control over the population and thereby playing a significant role in political responses to the Internet.

In Laos, Internet development forms part of a transition process aimed at integrating the country into the global market place. Here the government has been resistant to the Internet, the notion of a free flow of information running contrary to the state's centralised control of information. The fact that the need for centralised political control is tied to notions of societal boundedness, which in the case of the Lao nation state are perceived to be precarious and perilous, complicates the matter even further. Nonetheless, in recognition of the growing significance of electronic communications in today's global market, the government has, albeit reluctantly, accepted the introduction of the Internet. Internet 
connectivity was first established following Laos' entry into Association of South East Asian Nations (ASEAN), the organisation's reliance on electronic communications leaving the country little choice but to accept the establishment of a local gateway to the Internet. The fact that Internet development has been mostly dynamic in tourist areas is another indicator of the extent to which the Internet forms part of the country's transition into regional and global webs of exchange and interaction.

By contrast, in Malaysia, the government has made a concerted effort to incorporate the Internet in its modernisation efforts, making it an integral part of the country's Vision 2020. Here the government has played a proactive role in spreading the Internet throughout society. Following a long history of regional and global trade, Malaysia has not only decided to use the Internet to maintain its global positioning but also to enhance it. Paying heed to the notion of leapfrogging, the Internet forms part of the country's ambitious plans to achieve modernity by year 2020. It also forms part of its ambitions to become an equal global actor, the symbolic expression of which is the Multimedia Super Corridor (MSC), Malaysia's indigenous version of the Silicon Valley. Nonetheless, not fully recognising the social and cultural embeddedness of the Internet, the government has found itself in a digital dilemma. The promotion of a decentralised media technology that is defined by its ability to allow for a free flow of information has had certain unintended consequences for the country's centralised political structure. At a time of political upheaval, following the financial crisis of 1997 and 1998, the Internet provided an unprecedented opportunity for the political opposition, and for the average disgruntled citizen, to voice their discontent. In fact, the gains of the political opposition in the general elections of November 1999 have partially been attributed to the availability of the Internet. It has been suggested that the government's recent crack down on the country's on-line newspaper, Malaysiakini, has been undertaken to pre-empt similar developments in the next elections.

The experiences of Laos and Malaysia exemplify the trans-national dynamics of Internet development. In using the term trans-national I wish to underline the fact that these developments are 'trans-national', i.e. as much as they extend beyond it, they continue to be defined by the national (Hannerz 1996, p. 6). This interrelation between the national and trans-national becomes all too evident in the social dynamics of Internet development, the state playing a significant role in the introduction and subsequent development of networks that allow individuals to communicate and interact on a global scale. In other words, Internet development is emblematic of the paradoxical movement of integration and disintegration that has characterised nation-building efforts since their inception, a process in which transformations in communications have played a key role (Anderson 1998, pp.59-66). In more abstract terms, one can interpret these trans-national dynamics in terms of the contradictory interrelations between networks of flow and bounded structures. On the one hand, we are witnessing the growing significance of trans-national networks, the Internet enhancing global interconnectedness by tying people and places into global webs of decentralised communication and interaction. On the other hand, most people continue to live their lives in specific places, the boundaries of which are guarded and maintained by hierarchical state structures. These bounded structures may not fully correspond to a social reality of crosscutting networks. If 
anything, the social dynamics of Internet development in Malaysia and Laos illustrate the extent to which boundary-crossing networks represent a political dilemma for centralised and hierarchical state structures.

In light of the continued, albeit contradictory, role of the state in the networked world order, it would appear that we need to pay closer attention to the relation between the Internet and modernity. Rather than proclaiming the emergence of a post-modern network society, we should try and understand the processes of transformation that the networked society entails. As briefly outlined here, some of the most challenging aspects of the networked world order relate to the coexistence of trans-national, boundary crossing networks and bounded state structures. Although these trans-national dynamics are having an impact on societies around the world, they are far from predictable.

For developing countries, the challenges of the networked world order become particularly pronounced. While modernity continues to be associated with the construction of bounded nation-states, the process of modernisation is increasingly dependent on a society's ability to embrace the organisational principle of networks. In today's interconnected world, a country's inclusion in world society is increasingly tied to its ability to negotiate trans-national networks of global flow. If anything, the ability to use the Internet in a strategic manner has become and is becoming more significant for not only economic but also social development. Increasingly, social inclusion is understood in terms of Internet access, as exemplified by the discourse on the digital divide. Nonetheless, in order to appreciate the social impact of the Internet, one needs to go beyond the bipolar dichotomy of inclusion and exclusion. I am by no means suggesting that we should ignore the uneven distribution of Internet access around the world. Quite the contrary, existing digital discrepancies serve as a reminder to all of us of the need to address the root causes of social inequalities around the world. However, the Internet is having an impact that goes well beyond connectivity. By tying together societies around the world in a network of networks, the Internet is affecting the fundamental premises of our world order. Boundedness and separation is increasingly giving way to global interaction, as societies around the world become part of a networked world order.

\section{Global Exposure and 'Glocal' Interaction}

Globalisation can be viewed as a process that entails the actual making of the world as a whole as well as a growing consciousness thereof (Robertson 1990; 1992). In other words, globalisation is both a structural and a conceptual process. At the structural level, globalisation refers to all phenomena that contribute to making the world smaller, binding together different parts of the world into a web of interconnectedness. The Internet is clearly such a phenomenon, representing, as it does, a global communications infrastructure. The Internet is also a global phenomenon at the more abstract conceptual level. By providing a means with which people can communicate and interact with one another, regardless of physical distance, the Internet is raising awareness of the world as a whole. Globalisation is essentially a process of cultural blending. Rather than representing a unilateral movement from centre to periphery, global flows take place in the interaction between a diversity of cultures and cultural actors. The results of this process is a complex mixture of the global and the local, the 
universal and the particular, the interplay of which is better captured by hybrid-oriented concepts such as creolisation (Hannerz 1990; 1996) or glocalisation (Robertson 1995) than the one-sided connotations of terms like homogenisation, Americanisation or westernisation.

The Internet is an instructive example of glocalisation. Ever since anthropologists started mapping Internet use in different parts of the world, it has become clear that this window to the world offers a clearer perspective on one's place in it. If anything, the engagement in global cultures is complemented by a reinvigorated sense of national identity, along with a desire to inform the cultural 'other' about it (Miller and Slater 2000, pp. 97-98). In other words, it is in relation to 'others and elsewheres' that Internet users are able to and feel encouraged to partake in the process of 'defining and redefining' their own cultural identities (ibid.).

'Glocal' connections are also a recurring theme in my own ethnography on Internet pioneers. In spreading the Internet throughout the developing world, Internet pioneers have been influenced by, and in turn influenced, the cosmopolitan ethos of the culture of networking. Whether phrased in terms of a 'window to the world' or 'a global library', in their interpretations of what the Internet represents to them, an overwhelming majority of Internet pioneers have referred to its global reach as one of the most significant aspects of the Internet. The cosmopolitan worldviews of the Internet pioneers is a reflection of their transnational lifestyles. Belonging to a transnational elite of well-educated professionals, Internet pioneers are used to travelling around the world. Whether they come from developed or developing countries, they share the experience of working overseas. In the case of Internet pioneers from developing countries, their own exposure to the Internet has often taken place while undertaking higher education in more advanced countries. Upon return to their countries of origin, they have pioneered the introduction of the Internet, not least to be able stay in touch with their overseas friends and colleagues.

Its global reach is one of the main reasons why Internet pioneers are devoted to spreading Internet access throughout the developing world. To them the Internet offers an unprecedented opportunity for people to access a global resource of information. It also allows users to participate in cross-cultural encounters and to maintain trans-national links. To its pioneers, the Internet is not only making the world smaller, but it is also making it more accessible for developing countries. And it is the notion that the Internet is a social and cultural equaliser that motivates its pioneering champions. From the vantage point of its pioneers, it appears that the Internet is doing to cosmopolitanism what print capitalism did for nationalism, enabling a sense of solidarity with a fraternity that stretches far beyond the immediate social environment. It has already been ascertained that one of the factors contributing to the construction of the imagined communities of nations has been the evolution of new means to disseminate information, at the time print capitalism (Anderson 1983). Just like print media provided an interpretative lens through which to appreciate the delineated boundaries of the nation, thus facilitating the construction of nation states, the Internet enables users to perceive the world at large, cyberspace illustrating the creation of a virtual cosmopolis. In this regard, one can interpret the Internet in terms of a communications revolution that is contributing to 'the formation of world society as a single interactive network' (Hart 2000, p. 59). 
Among scholars, the cosmopolitan identification with the world at large is usually contrasted with commonly held identities, the nature of which tends to be far more parochial, binding the individual to a specific, bounded space. This holds particularly true when cosmopolitanism is compared with nationalism, the correlation with which tends to be problematic (see Robbins 1998). Critics of cosmopolitanism tend to question the extent to which social bonds and loyalties can be maintained by individuals whose identities stretch everywhere, yet reside nowhere, while proponents tend to emphasise the greater loyalties created through the identification with humanity at large. These opposing views tend to be influenced by how nationalism is perceived in the first place. To its proponents, the nation state represents the only viable means of political organisation and action in modern complex societies (e.g. Jameson and Miyoshi 1999), while its critics are perturbed by the propensity for violent activities that are carried out in the name of an artificial division of humanity into various configurations of us versus them (e.g. Appadurai 1996).

The perspectives of the Internet pioneers indicate that cosmopolitanism does not necessarily negate nationalism per se. To the Internet pioneers, cosmopolitanism represents a complementary identity, one that corresponds to their own trans-national existence, on-line as well as off-line. Unlike nationalism, it allows them to identify with a world that is global in scope, reaching well beyond the national boundaries that they themselves regularly cross. But while they identify with the world at large, they generally maintain a sense of belonging to a certain nation. Indeed, in many instances, their activities contribute to the very process of nation building, be it in their country of origin or elsewhere in the world, illustrating that one can indeed be a cosmopolitan patriot (Appiah 1998). The experiences of its pioneers suggest that far from erasing existing identities, the Internet facilitates their exploration, manipulation and continuation, within the framework of a more integrated global whole. Although some observers insist on interpreting the Internet as a vehicle for cultural homogenisation, I have found no empirical evidence for such postulations. Quite the contrary, the global reach and interactive nature of the Internet allows for a larger degree of cultural malleability. This cultural malleability is all too evident in the perspectives and activities of the Internet pioneers, suggesting that rather than representing an instance of cultural detachment 'actually existing cosmopolitanism is a reality of (re) attachment, multiple attachment, or attachment at a distance' (Robbins 1998, p. 3).

\section{The Mediation of Cultural Boundaries}

As much as the Internet highlights the ambiguity of cultural boundaries, it also provides a means with which to mediate their meaning. Media represent 'machineries of meaning' that allow people to participate in the process of 'cultural management' (Hannerz 1992b). Through media, the creation, externalisation and distribution of meaning takes place among social actors who are not in physical proximity with one another. Depending on its characteristics, each medium carries its own possibilities as well as constraints when it comes to the management of meaning (ibid., p. 27). In the case of the Internet, individualised interaction and communication on a global scope provides users with the means to manage the meaning of the world at large as well as their own place in it. 
As discussed above, by exposing users to the world at large, the Internet has a tendency to reinforce a localised sense of belonging. In this regard, the Internet helps clarify existing boundaries, encounters with the cultural 'other' having a tendency to reinforce the boundaries of one's own cultural identity. At the national level, the Internet is having a similar effect. As discussed earlier, Internet development is closely linked to nation building, including the state's response to global trends. In some instances, the Internet is even used for on-line nation building, a subject that I have explored more fully elsewhere (Uimonen forthcoming). Nonetheless, the Internet is changing the scope of cultural boundaries. In the past, the nation state represented the primary means of identification with an imagined community that reached well beyond the immediate physical environment. For many people, the nation was their whole world. In our networked world order, the world has become both larger and smaller: larger in the sense that we are more aware of the complexity and diversity of the world at large; smaller in the sense that we are more exposed to the interrelations of the world as a whole. Far from representing a clearly bounded, finite entity, the nation is increasingly perceived as one among many, while the ability to communicate and interact with others over the Internet is projecting an image of a networked world order.

The Internet is increasingly influencing the construction and reconstruction of nationalist imageries among individual citizens. In exposing users to the world at large, the Internet is creating a heightened awareness of the cultural composition of different societies. Through communication and interaction, users are in a better position to reflect upon and manage the meaning of their own cultural identity. The projection of nationalist imageries may be articulated through multimedia websites, or in interactive dialogue over electronic mail. It may emerge in discussions in on-line chat rooms, or in the linking of a site to related sources of information. Regardless of application, the Internet provides users with the means to mediate the meaning of their own cultural boundaries. The act of mediation is inherent to the Internet, the role of brokering representing an important component of the organisational principle of networking. In anthropological network studies, a broker is 'a person with a particular kind of network range' (Hannerz 1980, p. 190). Typically, the broker uses his/her network in such a way that he/she 'facilitates contacts among persons, groups, or institutions which are otherwise not within easy reach of one another' (ibid., p. 191, emphasis in original). In the case of Internet development, brokering is the primary means with which connections are established between members of different networks.

The experiences of its pioneers illustrate the extent to which the Internet serves as a medium for cultural brokering. In promoting its development, Internet pioneers engage with a number of actors, not least political decisionmakers. While the pioneers' understanding of the Internet is informed by the culture of networking, their interactions with external actors require a certain degree of translation. In this regard, the awareness raising activities that Internet pioneers are involved in represent instances of mediation between actors who have different understandings of the Internet, depending on their own social and cultural context. The success of these awareness-raising activities is largely determined by the Internet pioneers' ability to negotiate such differences and to identify an acceptable consensus. More broadly speaking, the aspect of broker- 
ing can refine our appreciation of the organisational logic of networks. For one thing, the role of brokers introduces an element of social segmentation in the relatively flat structure of networks, since the ability to play a brokering role requires a strategic positioning in different networks. More importantly, the act of brokering provides a means with which to connect disparate nodes and networks. Consequently, brokering contributes to a greater degree of overlap between various networks, thus facilitating a higher degree of interconnectedness, and by extension a greater degree of social cohesion.

In more abstract terms, the mediating character of the Internet can help us understand, and perhaps overcome, some of the contradictions inherent in modernity. Although modern society is based on the premise of separation and categorisation, the primary example of which is the bounded nation state, Latour (1993) argues that the promises of the modern constitution have never been realised. Rather than following predetermined categories, he suggests that 'everything happens in the middle' by way of 'mediation, translation and networks' (ibid., p. 37). The problem is that this in-between space 'does not exist', it is the 'unthinkable, the unconscious of the moderns' (ibid.).

Rather than pursuing a modernist agenda that is based on the premises of societal boundedness, perhaps it is time to rethink our societies in terms of networks of interconnectedness. This would allow us to appreciate the opportunities, as well as the risks, of the networked world order. In a world where societies are interconnected through boundary crossing networks, the Internet provides a means with which to mediate cultural difference and engage in cultural brokering. After all, by providing individual users the opportunity to engage in and interact with one another around the world, the Internet holds the potential to create a truly global society.

Meanwhile, there are great risks involved in ignoring the social and cultural implications of the networked world order. Greater global exposure and interaction does not necessarily lead to greater understanding and appreciation. To many people, the realisation of their place in the world leads to even greater dissatisfaction and disgruntlement. If anything, as we reach a greater degree of interconnectedness we can ill afford to ignore the plight of the socially excluded and marginalised. They may very well take this opportunity to interact with the privileged few through acts of violence and social disruption, and they are quite likely to use the Internet to organise their acts of defiance.

\section{Concluding Remarks: Networks of Global Interdependence}

In the networked world order, societies are interconnected. They are also interdependent. On 11 September 2001 we witnessed the extent of global interdependence, disgruntlement in the world's peripheries turning into violent attacks on the world's centres. On 12 October 2002, we witnessed another violent expression of global interdependence, this time on the island of Gods, Bali. Targeting symbols of Western decadence, terrorists wreaked havoc with the island's tourism industry, leaving millions of Balinese to suffer the economic consequences of events over which they have little control.

In this interconnected world of ours, we have learned that networks defy existing boundaries. Networks of terrorists are striking at people and places around the world, and while we know that the nodes of these networks consist 
of individuals who reside in specific locations, their mobility makes them very evasive. In coming to terms with these networks of violence, we are striking against territorially bounded states. In our search for terrorist nodes, we seek to identify societies that can be held responsible for the acts of networks. In so doing, we rally national support for our cause, patriotism helping us find meaning in death and violence.

The so-called war on terrorism seems to indicate that while we have become more aware of global interconnectedness, we have yet to appreciate the extent of global interdependence. Rather than trying to understand the linkages between us and them, we try to insulate ourselves from the cultural 'other', casting our differences in terms of a clash of civilisations. Meanwhile, we are turning a blind eye to the causes of grievances, focusing instead on their violent articulations.

In a world where we are able to communicate and interact with one another across cultural boundaries, we have yet to understand and appreciate our interdependence, let alone take responsibility for it. In the networked world order, no society, no matter how large or small, is isolated from the networks of power and resistance that envelop our interconnected world. Although the Internet is no panacea, this interactive network of networks can help us realise our global interdependence and mediate a more peaceful coexistence among the peoples of the world.

\section{References}

Anderson, B. (1983) Imagined Communities. Reflections on the Origin and Development of Nationalism (London, Verso).

Anderson, B. (1998) The Spectre of Comparisons: Nationalism, Southeast Asia and the World (London, Verso).

Appadurai, A. (1996) Modernity at Large. Cultural Dimensions of Globalisation (Minneapolis, University of Minnesota Press).

Appiah, K.A. (1998) 'Cosmopolitan patriots', in: P. Cheah and B. Robbins (Eds), Cosmopolitics: Thinking and Feeling beyond the Nation (Minneapolis, University of Minnesota press).

Barth, F. (1992) 'Towards greater naturalism in conceptualising societies', in: A. Kuper (Ed.), Conceptualising Society (London, Routledge).

Beck, U. (1994) 'The reinvention of politics: Towards a theory of reflexive modernization', in: U. Beck, A. Giddens and S. Lash (Eds), Reflexive Modernization. Politics, Tradition and Aesthetics in the Modern Social Order (Cambridge, Polity Press).

Castells, M. (1996) The Information Age. Economy, Society and Culture, Vol. I: The Rise of the Network Society (Oxford, Blackwell Publishers).

Castells, M. (1998) The Information Age. Economy, Society and Culture, Vol. III: End of Millennium (Oxford, Blackwell Publishers).

Castells, M. (2001) The Internet Galaxy. Reflections on the Internet, Business, and Society (Oxford, Oxford University Press).

Hafner, K. and Lyon, M. (1996) Where Wizards Stay Up Late. The Origins of the Internet (New York, Simon and Schuster).

Hannerz, U. (1980) Exploring the City. Inquiries Toward an Urban Anthropology (New York, Columbia University Press).

Hannerz, U. (1990) 'Cosmopolitans and locals in world culture', in: M. Featherstone (Ed.), Global Culture. Nationalism, Globalization and Modernity (London, SAGE Publications).

Hannerz, U. (1992a) 'The global ecumene as a network of networks', in: A. Kuper (Ed.), Conceptualizing Society (London, Routledge).

Hannerz, U. (1992b) Cultural Complexity. Studies in the Social Organization of Meaning (New York, Columbia University Press). 
Hannerz, U. (1996) Transnational Connections. Culture, People, Places (London, Routledge). Hart, K. (2000) The Memory Bank. Money in an Unequal World (London, Profile Books) http://www.thememorybank.co.uk.

Jameson, F. and Miyoshi, M. (Eds) (1999) The Cultures of Globalization (Durham, Duke University Press).

Latour, B. (1993) We Have Never Been Modern (Cambridge, Massachusetts, Harvard University Press).

Miller, D. and Slater, D. (2000) The Internet: An Ethnographic Approach (Oxford, Berg) http:/ / ethnonet.gold.ac.uk.

Nua Internet Surveys, http://www.nua.com/surveys/how_many_online/index.html, last viewed September 2002.

Naughton, J. (2000) A Brief History of the Future. The Origins of the Internet (London, Orion Books).

Robbins, B. (1998) 'Introduction part I: Actually existing cosmopolitanism', in: P. Cheah and B. Robbins (Eds), Cosmopolitics: Thinking and Feeling beyond the Nation (Minneapolis, University of Minnesota press).

Robertson, R. (1990) 'Mapping the global condition: Globalization as the central concept', in: M. Featherstone (Ed.), Global Culture. Nationalism, Globalization and Modernity (London, SAGE Publications).

Robertson, R. (1992) Globalization. Social Theory and Global Culture (London, SAGE).

Robertson, R. (1995) 'Time-space and homogeneity-heterogeneity', in: M. Featherstone, S. Lash and R. Robertson (Eds), Global Modernities (London, SAGE).

Schroeder, R. (1996) Possible Worlds. The Social Dynamic of Virtual Reality Technology (Boulder, Colorado, WestviewPress).

Uimonen, P. (2000) 'Networking for Democracy: The Internet and the Developing World', The Namibian 15th Anniversary Commemorative Magazine, August 2000.

Uimonen, P. (2001) Transnational.Dynamics@Development.Net: Internet, Modernisation and Globalisation, Stockholm Studies in Social Anthropology, 49 (Stockholm, Almqvist \& Wiksell International), http://www.i-connect.ch/uimonen.

Uimonen, P. (forthcoming) 'Mediated Management of Meaning: On-line Nation Building in Malaysia', in: Global Networks: a Journal of Transnational Affairs. 